\title{
PREVEALENCE OF INFECTIOUS BOVINE RHINOTRACHITIS VIRUS ANTIBODIES IN BOVINE SERUM IN MOSUL, IRAQ
}

\author{
M.SH. RHAYMAH, S.A. ESMAEEL, S.D. HASSAN and KH.J. HUSSAIN \\ Department of Internal and Preventive Medicine College of Veterinary Medicine, University of Mosul , Mosul, Iraq
}

\section{ABSTRACT}

Received at: 30/5/2012

Accepted:
The clinical singes of Infectious Bovine Rhinotrachitis (IBR) in cattle included rise in body temperature, keratoconjunctivitis, ulcerative lesions on muzzle and nasal septum, salivation, lacrimation, lesions at prepuse of male and pustule at the mucous membrane of valve and vagina in females. The seroprevalence of antibodies of Bovine Rhinotrachitis virus using indirect ELISA test in calves suffering from respiratory signs with genital lesion was $67.4 \%$, while $72.7 \%$ in aborted cows and $62.5 \%$ in cows suffering from keratoconjunctivitis . the mean of antibodies titer in calves appear respiratory singes with lesion at genitaria was $1.414 \pm 0.15$ in mild cases to $2.34 \pm 0.055$ in severe cases, while in aborted cows the mean titer of antibodies was $4.64 \pm 1.44$ to $125.55 \pm 8.68$ in mild and severe cases respectively in cows affected with keratoconjectivitis the mean of titer in severe cases was $65.9 \pm 15.96$ to $121.26 \pm 2.66$ in mild and severe cases respectively.

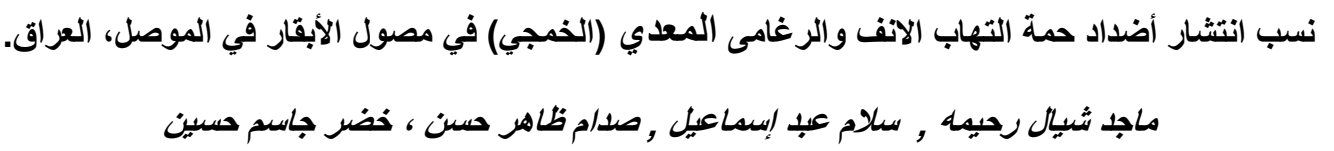

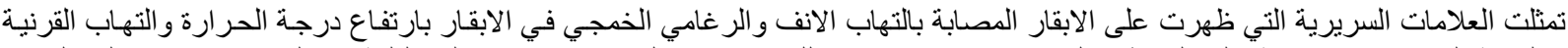

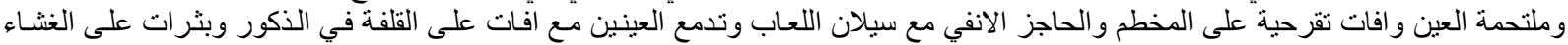

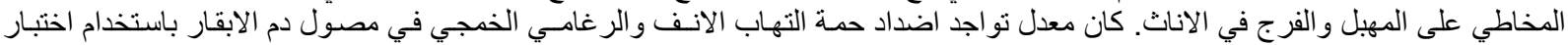

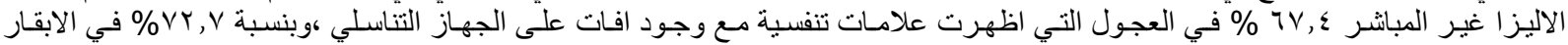

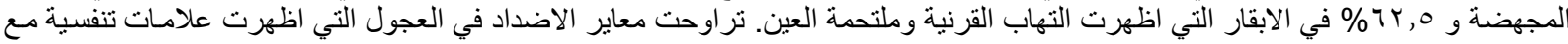

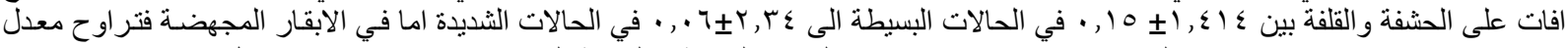

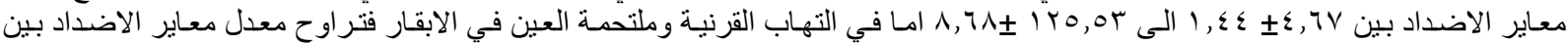
10,97士70,9

\section{INTRODUCTION \\ المقدمة}

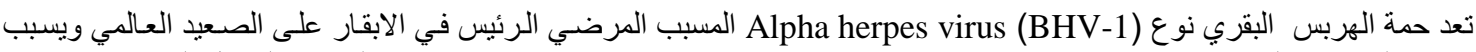

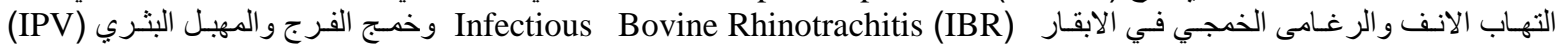
Infectious pustular vulvovaginitis

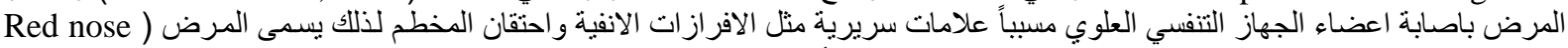

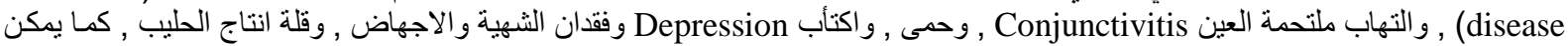

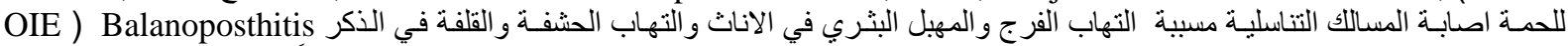

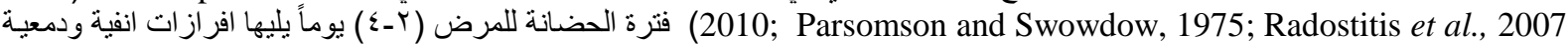
مخاطية ,مع سيلان اللعاب ,وبعد ايام عديدة تصبح الافرازات الانفية والدمعية مخاطانية قيحية (Miller,1991) .

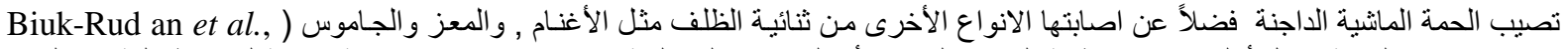

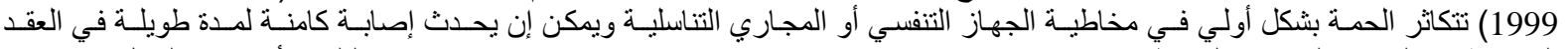

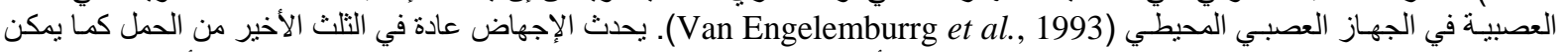

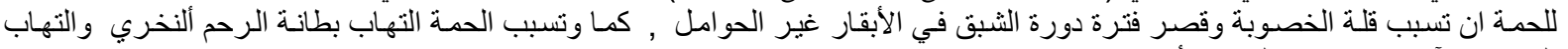

المبايض و آفات شديدة في الجسم الأصفر(Corpus Winkler et al., 2000; Murphy et al., 1999 ).

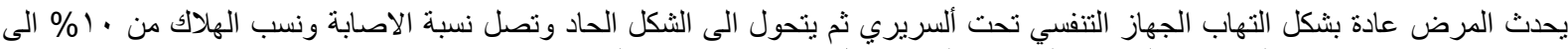

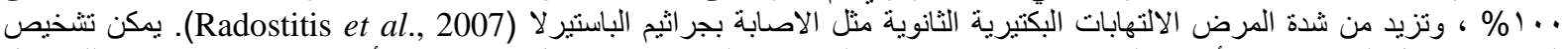

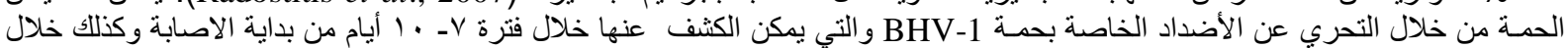


الطور الكامن للحمة ومن استخدام الاختبار ات المصلية منها اختبار تعادل الحمة Viral Neutralazationt test واختبار الاليزا و التي يعتد

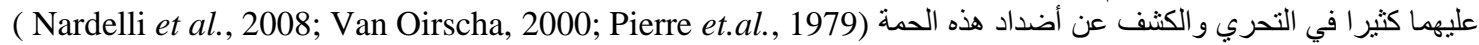

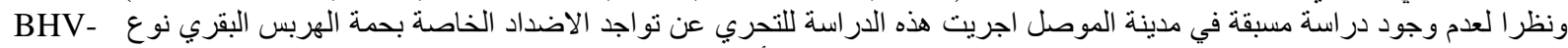

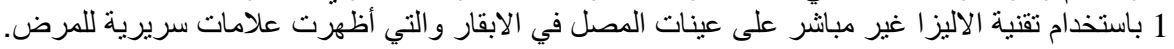

\title{
MATERIALS and METHODS \\ المواد وطر ائق العمل
}

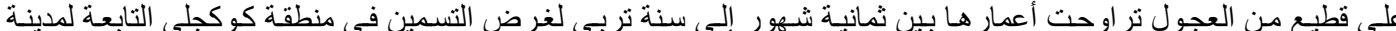

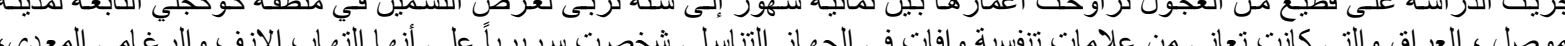

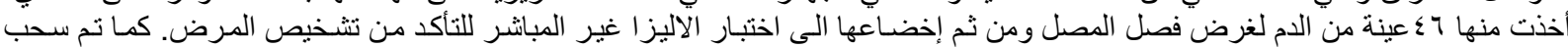

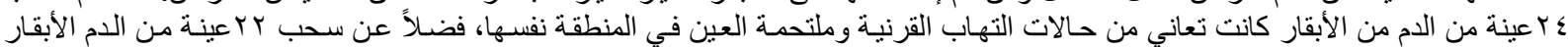

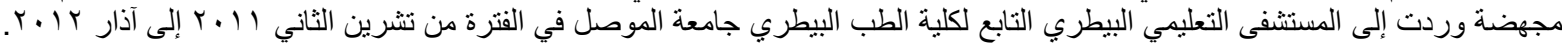

الاختبارات المصلية:-

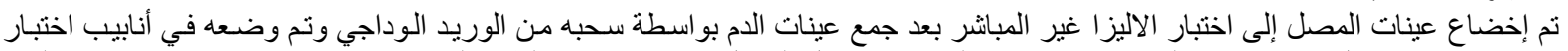

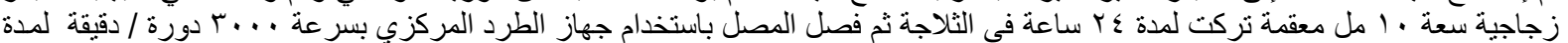

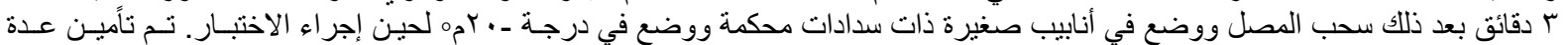

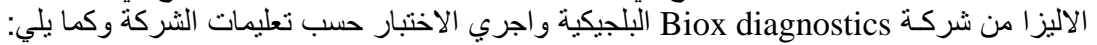

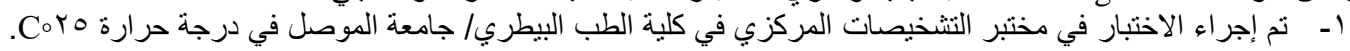

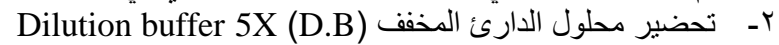

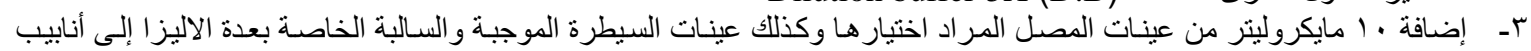

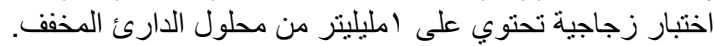

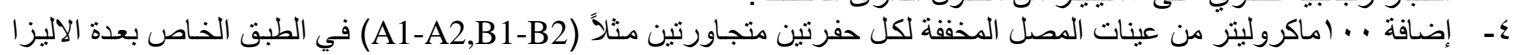

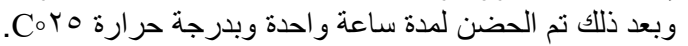

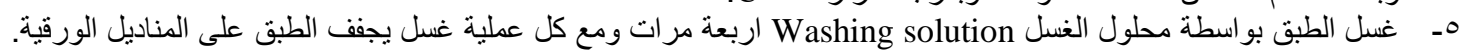

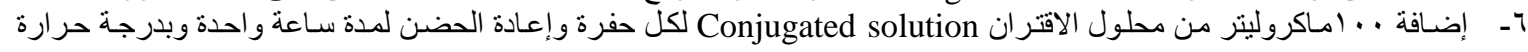
.COro

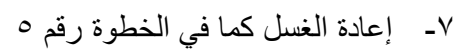

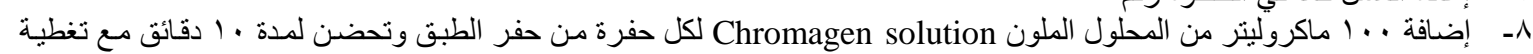

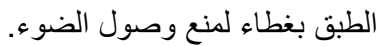

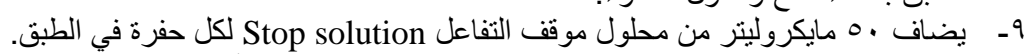

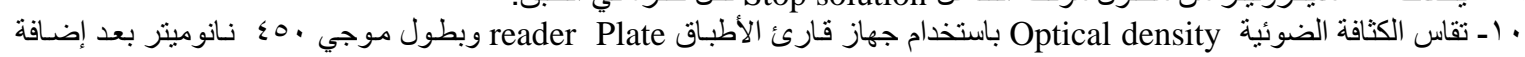
محلول موقف التفاعل. ال ـ قراءة النتائج واستخر اج نسبة تواجد معايير الاضداد لكل عينـة بعد استخر اج معدل كل حفرتين متجاورتين (A1-A2=S1) وحسب Val=delta OD Sample $\times 100 /$ delta OD positive المعادلة التالية:

\section{RESULTS النتائج}

تمثلت العلامات السريرية التي ظهرت على الحئ الحيوانات التي خضعت مصولها التها الى اختبار الاليزا غير المباشر للتقصي عن اضداد حمة التهاب

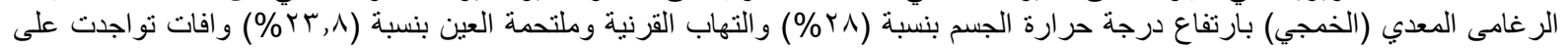

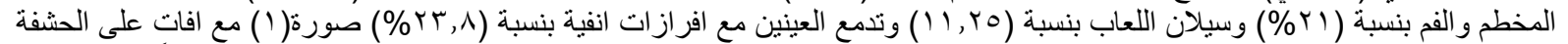

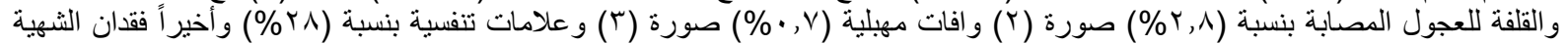

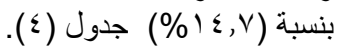

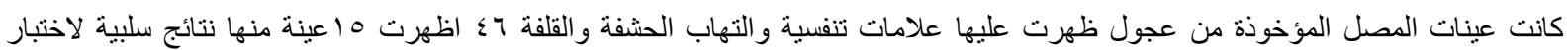

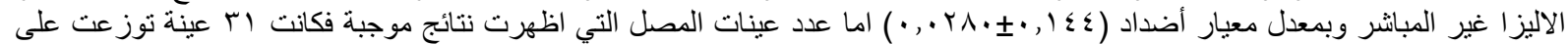

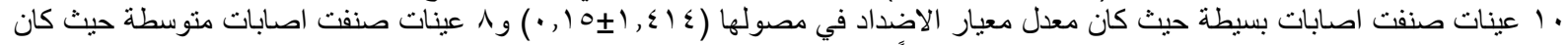

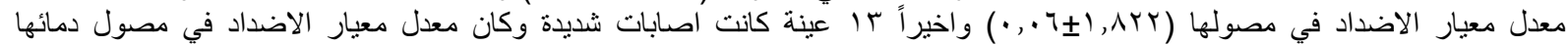

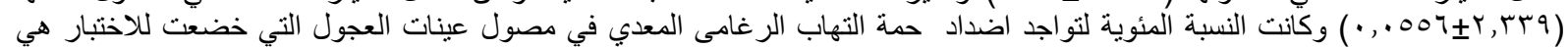

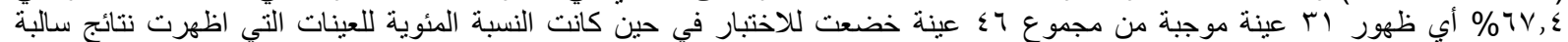

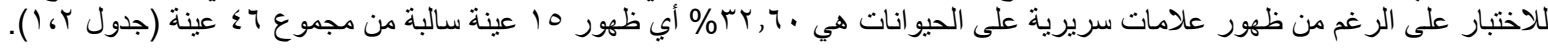

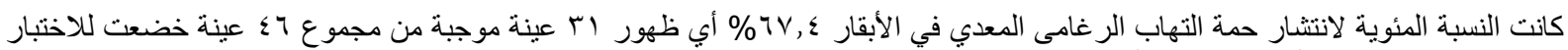

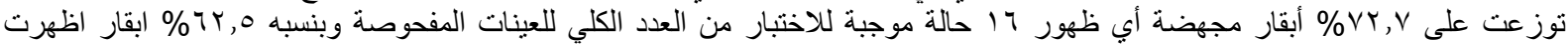

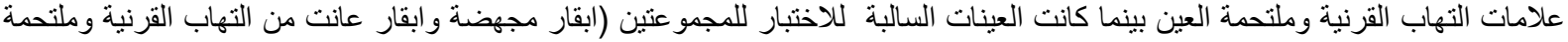

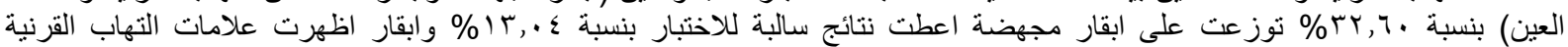

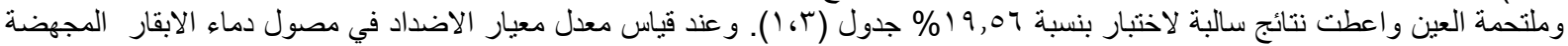

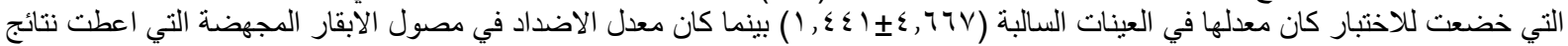

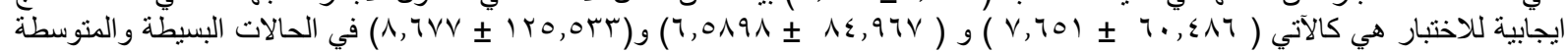




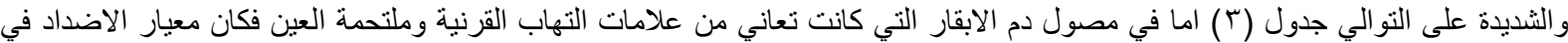

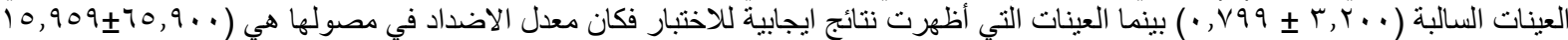

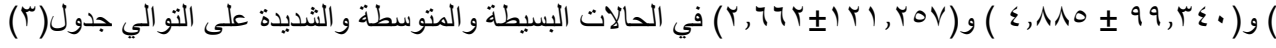

$$
\text { جدول ا : يبين النسب المئوية لتواجد الأضداد في حالات التهاب الرغامى المعدي في الأبقار }
$$

\begin{tabular}{|c|c|c|c|}
\hline النسبة المئوية للإصابة\% & عدد الحالات الموجبة & عدد الحالات الكلي & شكل المرض \\
\hline$\% T V, \varepsilon$ & 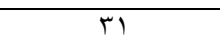 & $\leqslant 7$ & أعر اض تتفسية و التهاب الحشفة و القلفة \\
\hline$\% \vee Y, V$ & 17 & Kr & الإجهاض \\
\hline$\%$ \% & 10 & $r \varepsilon$ & التهاب القرنية و الملتحمة \\
\hline
\end{tabular}

جدول ب: يبين نسب انتشار أضداد حمه التهاب الرغامى المعدي في عجول التسمين(T؟عينة)

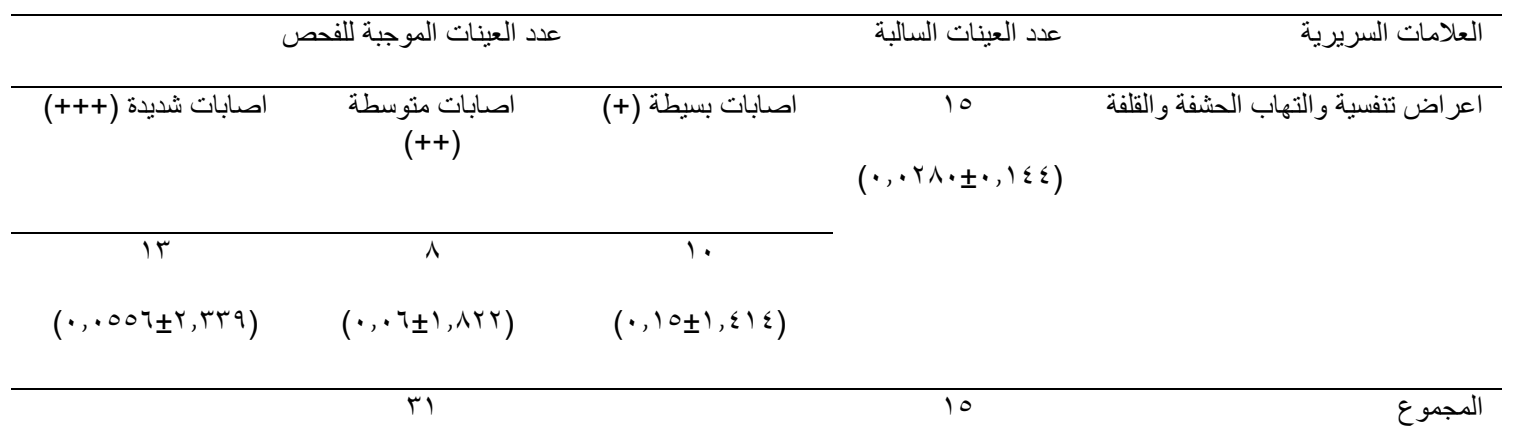

الأرقام بين الأقو اس تمثل المعدل 土 الخطأ القياسي (لمعايير الاضداد)

جدول r: يبين نسب انتشار اضداد حمه التهاب الرغامى المعدي في الابقار التي تعاني من الاجهاض والتهاب الملتحمة وقرنية العين.

\begin{tabular}{|c|c|c|c|c|c|}
\hline \multicolumn{3}{|c|}{ عدد العينات الموجبة للفحص } & \multirow[t]{2}{*}{ عدد الحالات السالبة } & \multirow{2}{*}{ الكلي } & \multirow{2}{*}{ 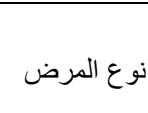 } \\
\hline اصابات شديدة +++ & اصابات متوسطة +++ & اصابات بسيطة + & & & \\
\hline $\begin{array}{c}r \\
\left(\Lambda, T V V_{ \pm} \mid r_{0}, 0 r r\right)\end{array}$ & $\begin{array}{c}\nearrow \\
(\urcorner, 0 \wedge 9 \wedge \pm \wedge \varepsilon, 97 \vee)\end{array}$ & $\begin{array}{c}V \\
(V, 701 \pm 7 \cdot, \leqslant \wedge 7)\end{array}$ & $\begin{array}{c}1 \\
(1, \varepsilon \varepsilon 1 \pm \varepsilon, 77 V)\end{array}$ & Yr & الإجهاض \\
\hline $\begin{array}{c}V \\
(r, T \pi Y \pm \mid r), Y \circ V)\end{array}$ & $\begin{array}{c}0 \\
(\varepsilon, \wedge \wedge 0 \pm 9 q, r \leqslant \cdot)\end{array}$ & $\begin{array}{c}r \\
(10,909 \pm 70,9 \ldots)\end{array}$ & $\begin{array}{c}q \\
(\cdot, \vee \vee q \pm r, r \cdot \cdot)\end{array}$ & $r \varepsilon$ & والملتحمة القرنية \\
\hline 1 . & 11 & 1. & 10 & $\varepsilon 7$ & المجموع \\
\hline
\end{tabular}

الأرقام بين الأقواس تمثل المعدل 土 الخطأ القياسي (لمعايير الأضداد)

جدول ؛ : العلامات السريرية ونسب تكر ارها في العجول الأبقار الخمجة بحمة التهاب الرغامى الخمجي

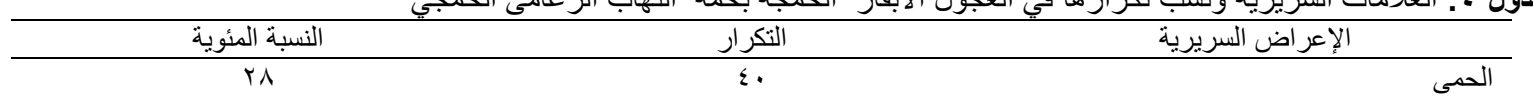

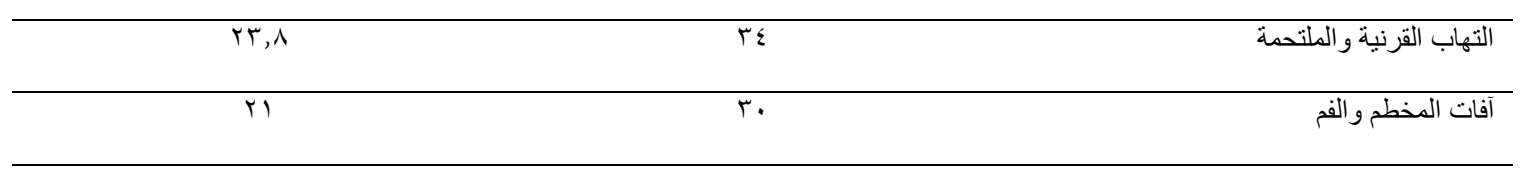


Assiut Vet. Med. J. Vol.58 No.134 July 2012

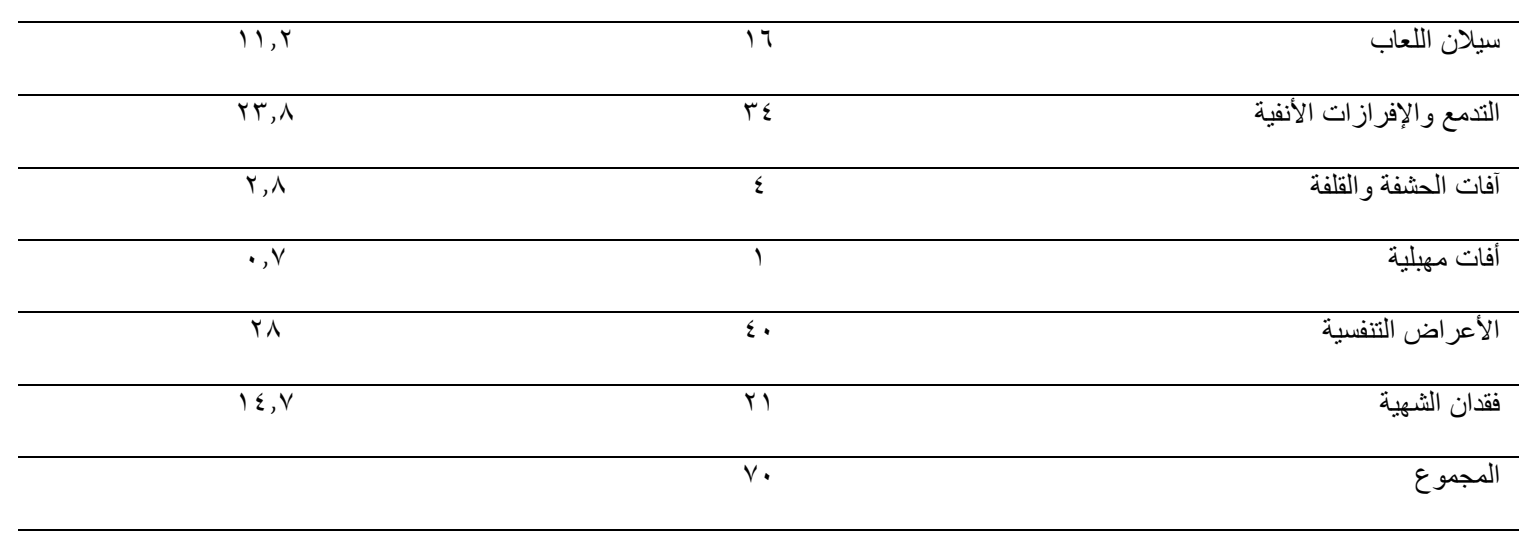

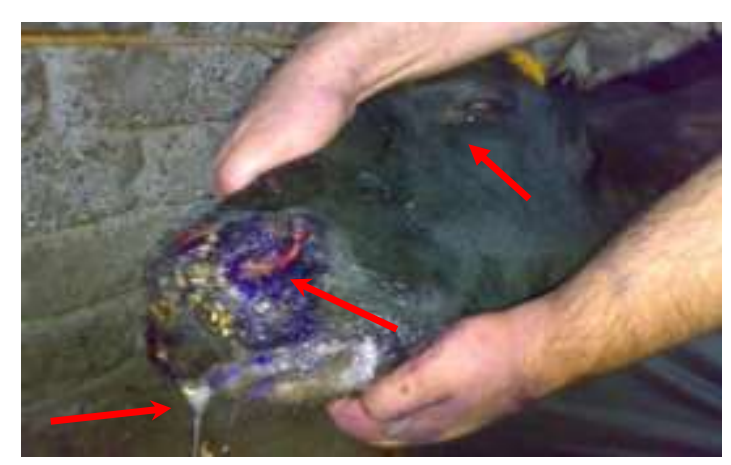

$$
\text { صورة ا : يبين وجود آفات على الفم والمخطم وسيلان اللعاب وتدمع }
$$

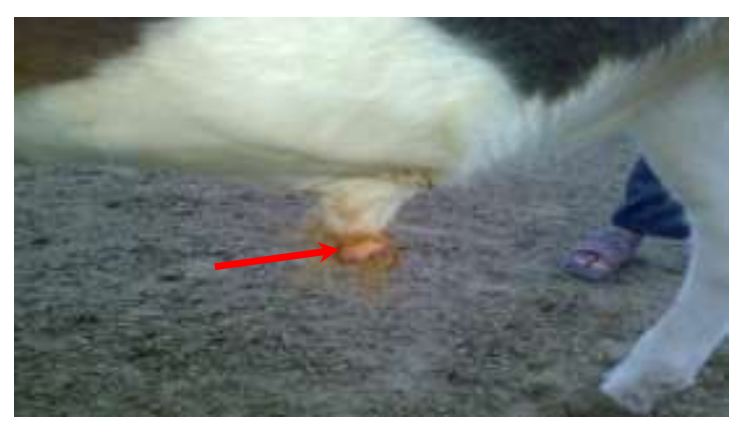

صورة ب : تبين وجود الآفة المرضية على الحثفة

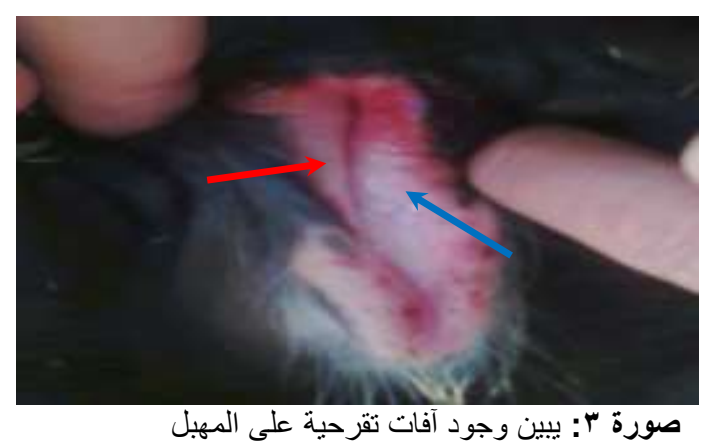

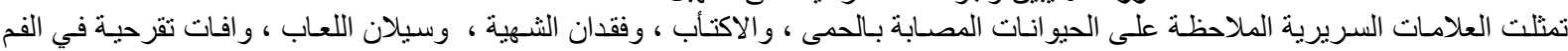

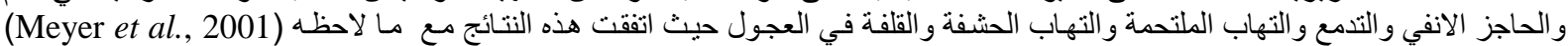

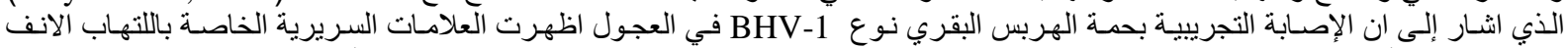

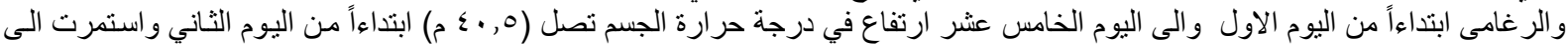

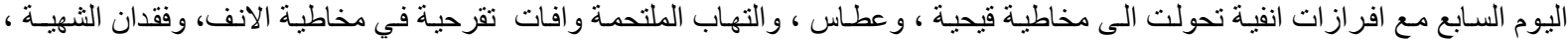

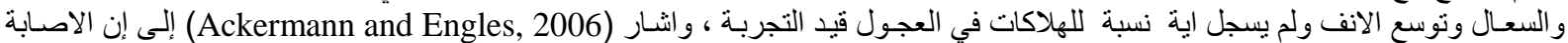

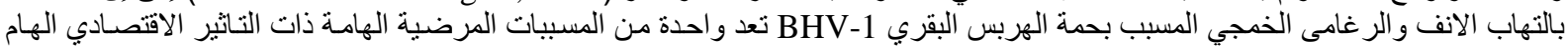

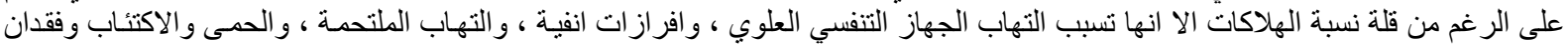
الثـهية ، وسيلان اللعاب مـع قلة في انتاج الحليب ، كمـا اشـار (Aboelzein et al., 2008) خلال حدوث ثورة مرضية في المملكة العربية 


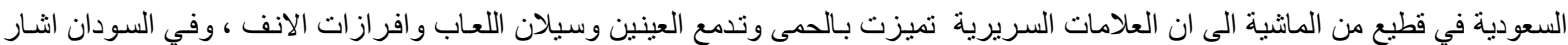
(Eisa, 1983)

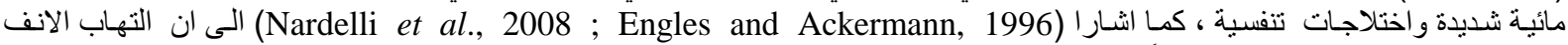

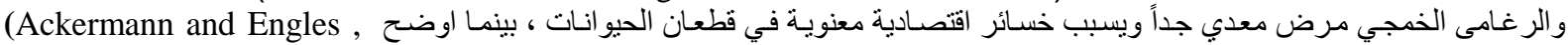

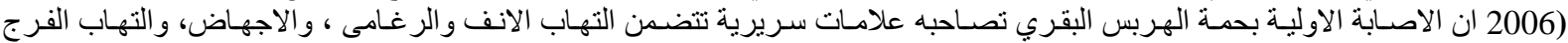

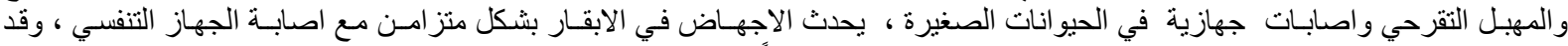

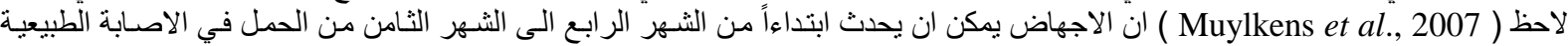

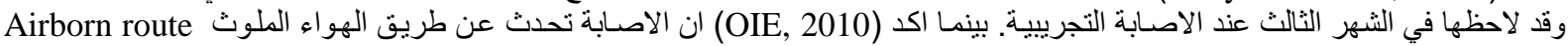

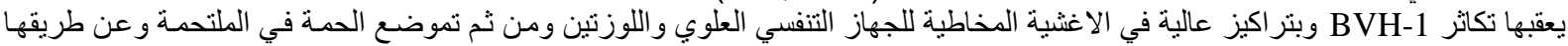

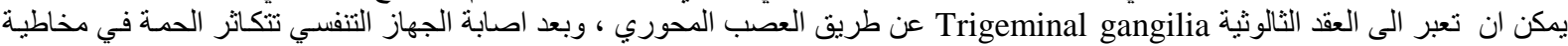
المهبل او الحشفة وتصبح بشكل كامن في العقد العصبية العجزية Sacral gangilia.

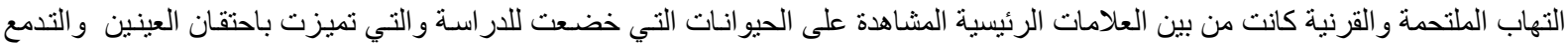

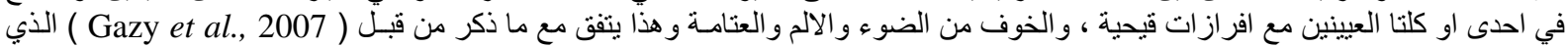

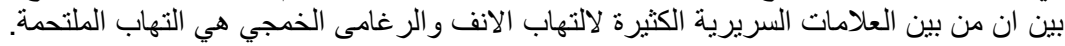

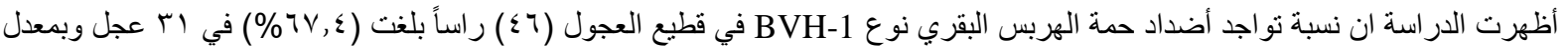

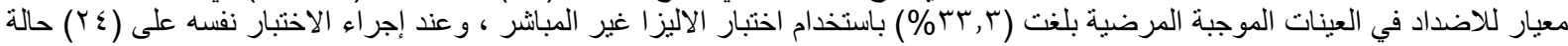

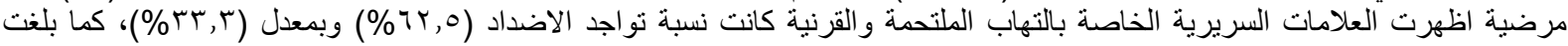

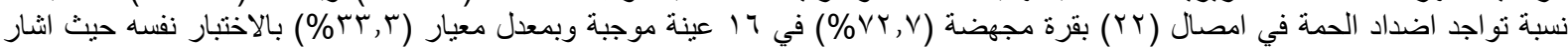

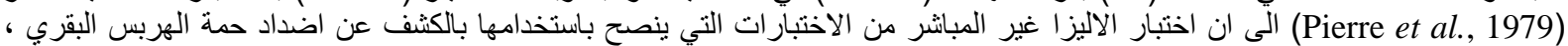

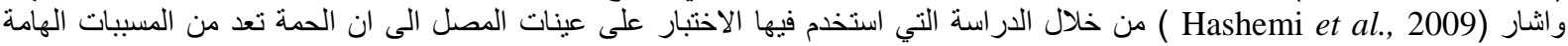

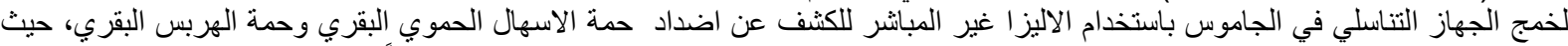

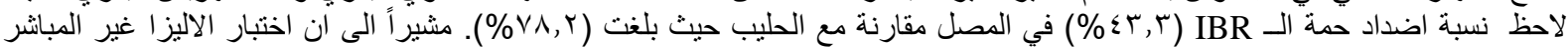

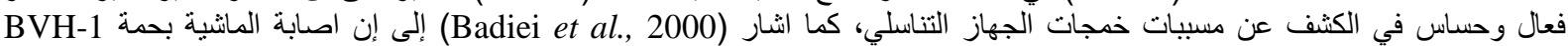

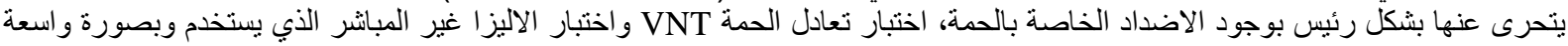

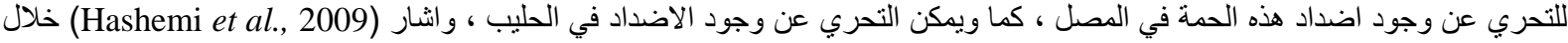

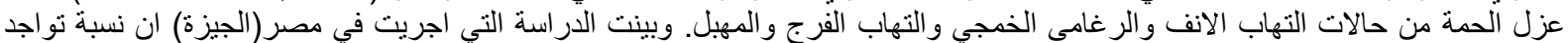

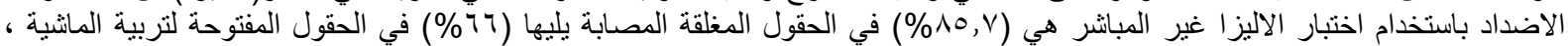

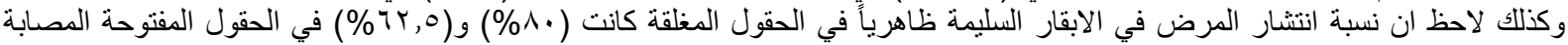

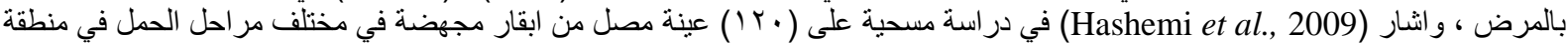

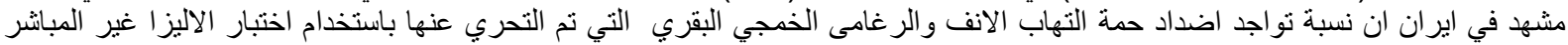

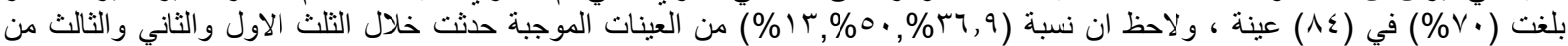
الحمل على التوالي.

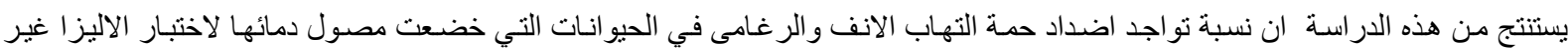

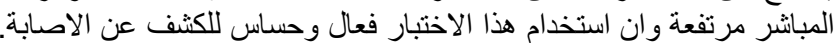

\section{REFERENCES}

المصادر

Aboelzein, E.M.; Housawi, F.M.T.; Al-Faleq, A.L. and AL-Musa, J. (2008): Emergency of clinical infectious bovine rhinotracheitis in eastern Saudi Arabia Rev. Elev. Med. Vet. Pays tropcau, 61(1): 11-13.

Ackermann, M. and Engles, M. (2006): Pro \& contra IBR. Eradication, veterinary Microbiology, 113:293-302.

Badiei, K.; Ghane, M.M. and Mostaghni, K. (2000): Seroprevalence of bovine herpes virus type 1 in the industrial dairy cattle herds in suburb of shiraz-iran, Australian, J. OF Basic \& applied science, 4(10): 4650-4654.

Banenfus, M.; Dehlli, Quadri, C.A.; Mcinture, R.W. and Schroeder, R.J. (1963): Isolation of Infectiuos bovine rhinotracheitis virus from calves with meningeoencephalitis. AM. Vet. Med. Assoc., 143: 725-728.

Biuk-Rud an, N.S.; Cvertic, J.J.; Madic, and Rudan, D. (1999): Prevalence of antibioticies to IBR anBVD virus in dairy cows with reproductive disorders, theriogenology 51: 875-881.

Eisa, M. (1983): Isolation of the virus of Infectious bovine rhinotrachitis in sudan. Sud. J. Vet. Res, 5: 65-68.

Engles, M. and Ackermann, M. (1996): Pathogenesis of ruminant herpes virus infectious veterinary Microbiology, 53: 3-15.

Gazy, A.A.; Ahmed, W.M.; Mohmoud and Larina, A. (2007): Prevalence of infectious bovine rhinotrachitis \&bovine viral diarrhea virus in female buffaloes with reproductive disorders \& parasitic infection.international journal of dairy scince 2(4): 339-347.

Hashemi tabar, G.R.; Rad, M.; Naseri, Z. and Azizzadeh, M. (2009): Detection of antibody against infectious bovine rhnotrachitis glycoprotein IgE in aborted cattle in Mashhad, iran,Archives of Rad institutes, 64(2): 91-95.

Meyer, G.; Lemaire, M.; Ros, C.; Belak, K.; Gabriel, D.; Cassart, F.; Coignoul, S.; Belak, S. and Thiry, E. (2001): Comparative pathogenesis at acute \& latent infectious of calves with bovine herpes type $1 \&$ Arch. Virol, 146: 633-652. 
Miller, M.J. (1991): The effefts of IBR virus infection on reproductive function on cattle. Vet. Med., 86: 95-98.

Murphy, F.A.; Gibbs, E.P.J.; Horzined, M.C. and Student, M.J. (1999): Herpes-viridae. veterinary virology,3rd Edt. In Academic press,U.S.A.

Murphy, F.A.; Gibbs, E.P.J.; Horzined, M.C. and Student, M.J. (1999): Paramyxoviridae in veterinary virology, 3rd Edt. In Academic press ,U.S.A. ,p:423.

Muylkens, B.; Thiry, J.; Kirten, P.; Schynts, F. and Thirty, E. (2007): Bovine herpes virus, infection \& infectious bovine rhinotracheitis, veterinary Research, 38: 181-209.

Nardelli, S.; Farina, G.; Lucchini, R.; Valocc, C.; Moresco, A.; Dalzotto, R. and Costanzi, C. (2008): Dynamics of infection \&immunity in adairy cattle population undergoing an eradication program for infectious bovine rhinotraachitis preventive veterinary medicine, $85: 68-80$.

OIE, (2010): Infectious bovine rhinotracheitis/ infectious pustular vuvlvovaginitis,vertion adopted by world assembly of delegated of the OIE in may.,OIE, terrestrial manual 2010.

Parsomson, I.M. and Swowdow, W.A. (1975): The effected of natural \& artificial breeding using bulls infected with, or semen containinated with infectious brain rhinotracheitis virus. Aust. Vet. J., 51: 365-369.

Pierre, P.; Robert, A.; Michel, T. and Paul, M. (1979): Enzyme-linked immunosorbent assay for serology of infectious bovine rhinotrachitis virus infectious. J. Clinic. Microbio. 10(5): 633-635.

Radostits, O.M.; Gay, C.C.; Hinchcliff, K.W. and Constable, P.D. (2007): Veterinary Medicine a textbook of the disease of cattle, horses, sheep, pigs and goats., $10^{\text {th }}$ ed. Edinburgh, London, New York, Oxford, Philadelphia, St Louis, Sydney, Toronto, pp :926

Van Engelemburrg, F.A.; Maes, R.K.; Vanorschot, J.T. and Rusemuk, F.A. (1993): Development of rapid \& sensitive polymerase chain reaction assay for detection of bovine herpes virus type 1 in bovine semen. J. Clin. microbial, 31: 3129-3135.

Van oirscha, J.T. (2000): Infectious bovine rhinotracheitis, infectious pustular vulvovaginitis in Manual of standarts for diagnostic test \&vaccines, $4^{\text {th }}$ ed. Paris office international des, epizootias, 381-391.

Winkler, M.T.; Doster, A. and Jones, C. (2000): Persistence \& reactivation of bovine herpes virus -1 in the tonsils of latently infected calves, J. Virology., 74: 5337-5346. 
Assiut Vet. Med. J. Vol.58 No.134 July 2012 